\title{
Mammary stem cells and cancer: roles of Wnt signaling in plain view
}

\author{
Alexander M Many and Anthony MC Brown*
}

\begin{abstract}
The likely roles of Wnt signaling in regulating mammary stem cell behavior have been much discussed, in part because they may underlie the oncogenic effects of Wnt signaling in mammary tissue. Two recent papers add important data to this field. One tests directly the effects of purified Wnt protein on mouse mammary stem cells in culture and finds a specific increase in the proportion of cells with self-renewing stem cell phenotypes. The second identifies a novel target gene of canonical Wnt signaling that may be expressed in stem cells and is induced in both mouse and human mammary tumors associated with Wnt pathway activation.
\end{abstract}

\section{Background}

Identifying the functional consequences of Wnt/ $\mathrm{B}$ catenin signaling in mammary stem cell populations is critically important for understanding the contribution of this pathway to mammary tumorigenesis. There is abundant evidence that hyperactivation of the canonical Wnt signaling pathway promotes tumorigenesis in experimental systems, while observational data demonstrate that the pathway is frequently activated in human breast tumors, especially in basal-like carcinomas, one of the most aggressive forms of the disease [1-3]. MMTV-Wnt1 transgenic mice provide a powerful model of Wnt signaling in mammary cancer, and also one in which the role of aberrant stem cell behavior may be paramount [4,5]. These mice develop premalignant mammary hyperplasia with elevated stem cell numbers [6], and their subsequent carcinomas contain a cancer stem cell population defined by methods similar to those applied to human breast cancers [7]. Meanwhile, studies of stem cells in other tissues, such as bone marrow, skin,

*Correspondence: amcbrown@med.cornell.edu

Department of Cell and Developmental Biology, Weill Cornell Medical College, New York, NY 10065, USA and intestine, have strongly implicated Wnt $/ \beta$-catenin signaling as a pathway that fosters the self-renewal, maintenance, and/or expansion of stem cells or multipotent precursors $[1,8,9]$. However, details at the cellular level remain to be established in each tissue, as do the downstream mechanisms through which Wnt signaling acts in each context.

\section{Viewpoint}

In a paper recently published in Cell Stem Cell [10], Zeng and Nusse made use of the epithelial cell surface marker phenotype $\mathrm{CD} 24^{+}$and $\mathrm{CD} 29^{\text {hi }}$ that identifies a population highly enriched for mouse mammary stem cells (MaSCs) [11]. The authors isolated these cells by fluorescence activated cell sorting (FACS) from mammary tissue and cultured them in matrigel, serum-free medium, and epidermal growth factor. Under these conditions, the cells formed clonal colonies containing differentiated cells as well as cells capable of generating new colonies upon serial passage. When purified Wnt3a protein was added to the primary cultures, the number of cells able to form secondary colonies was increased 2.5 -fold relative to vehicle-treated controls [10]. This expansion continued through multiple passages, yet the Wnt treatment had no obvious effect on the growth rate of individual colonies or their composition of differentiated cell types. Importantly, the Wnt-treated colonies retained their mammary gland reconstitution efficiency upon transplantation in vivo, confirming that definitive stem cell capacity was maintained as the relevant cells increased their numbers in culture.

The most important aspect of these results is the likely conclusion that Wnt proteins can act directly on MaSCs to promote their self-renewal or expansion. A direct response is further supported by evidence that some of the individual stem cells in vivo display activation of a Wnt-responsive lacZ reporter [10]. Previous data implicating Wnt signaling in the regulation of mammary stem cells in vivo could not generally distinguish between direct versus indirect effects (for example, on the stem cell niche). The present results also address temporal issues of cell fate control. Rather than causing a permanent change affecting all future cell divisions, the 
Wnt signal here was continuously required for maintenance of the self-renewing stem cell population [10]. This may reflect the effective absence of a niche in the culture conditions and a default tendency towards lineage differentiation. In contrast, once the Wnt-treated cells were transplanted in vivo, their self-renewal was maintained through serial transplants. This suggests that they found, or generated, a suitable niche in vivo, perhaps one that provides sustained Wnt signaling.

One interpretation of these results is that Wnt signals can replace the need for a physical stem cell niche. If something comparable takes place in MMTV-Wnt1 mammary tumors, in which Wnt signaling is constitutively activated, this could explain the prominence of stem cell transcriptional signatures in such tumors [12]. It is particularly pertinent to ask whether effects of aberrant Wnt signaling on cancer stem cells might underlie the aggressive phenotype of basal-like human breast cancers $[3,7]$.

Another question that arises from Zeng and Nusse's results concerns the mechanisms by which Wnt signals promote the self-renewal of MaSCs. A standard approach to this would be to scrutinize, in the stem cell population, transcriptional targets of the $\mathrm{T}$ cell factor (TCF)- $\beta$ catenin complexes through which canonical Wnt signals act in the nucleus $[1,8]$. Of several Wnt target genes that have been reported in mammary cells, a particularly intriguing candidate, $L B H$, has recently been described in Molecular and Cellular Biology [13].

LBH is a transcription cofactor named for its abundant expression in embryonic limb bud and heart, although it is also expressed in the mouse mammary gland $[13,14]$. Its expression in mouse limb bud ectoderm is largely coincident with canonical Wnt signaling and this prompted Rieger and colleagues [13] to ask if it might be a Wnt target gene. Their data comprehensively demonstrate that Lbh is a direct transcriptional target of TCF- $\beta$ catenin. This was borne out in the mammary cell line $\mathrm{HC} 11$, in which Wnt3a treatment induced endogenous Lbh expression. Moreover, exogenous expression of Lbh in $\mathrm{HC} 11$ prevented lactogenic differentiation, something that is also prevented by Wnt signaling in these cells $[13,15]$. This raises a possible connection between Wntmediated inhibition of stem/precursor cell differentiation and the functions of Lbh, whose overexpression in cardiac and other tissues has been associated with prolonged maintenance of immature cells at the expense of differentiation [13].

Turning to mammary tumors, Rieger and colleagues documented significant levels of Lbh mRNA in MMTVWnt1 mammary tumors. They also found high levels of LBH in estrogen receptor-negative human breast cancer cell lines of basal origin that have active endogenous Wnt signaling. Next they interrogated Affymetrix data from human breast carcinomas and found $L B H$ was most frequently associated with basal-type tumors, the form also associated with Wnt pathway activation $[3,13]$.

Collectively, these data build a solid case for $L b h$ as a transcriptional target that responds to canonical Wnt signaling in mammary tissue and Wnt-driven tumors. Its prevalence in highly aggressive basal-like human carcinomas makes it of particular clinical interest, at least as a marker, and conceivably as a therapeutic target in these difficult to treat tumors if it plays a role in their proliferation. There is preliminary evidence that Lbh may act as one of the functional mediators of Wnt signaling in the inhibition of HC11 cell differentiation, but these are early days for this newly revealed Wnt target [13].

A key question for this Viewpoint is whether $L b h$ is a TCF- $\beta$-catenin target gene in the mammary stem cells in which Zeng and Nusse describe the self-renewal effects of Wnt signaling. While this remains to be determined definitively, it is striking that a recent paper in Breast Cancer Research lists $L b h / L B H$ as one of the genes in a conserved gene expression signature characteristic of mammary stem cells in both mouse and human [12]. This raises the intriguing possibility that $L b h$ is one of the targets that mediate the functional effects of Wnt signaling on mammary tissue stem cells, and perhaps on stem-like cells in breast cancer.

Abbreviations

MaSC $=$ mammary stem cell; TCF $=$ T cell factor.

\section{Competing interests}

The authors declare that they have no competing interests.

\section{Acknowledgments}

The authors acknowledge support from the National Institutes of Health (CA123238), the Tri-Institutional Stem Cell Initiative, and NY State Department of Health (N08G-056).

Published: 22 September 2010

\section{References}

1. Clevers $\mathrm{H}$ : Wnt/beta-catenin signaling in development and disease. Cell 2006, 127:469-480.

2. Howe LR, Brown AMC: Wnt signaling and breast cancer. Cancer Biol Ther 2004, 3:36-41.

3. Khramtsov Al, Khramtsova GF, Tretiakova M, Huo D, Olopade OI, Goss KH: Wnt/beta-catenin pathway activation is enriched in basal-like breast cancers and predicts poor outcome. Am J Pathol 2010, 176:2911-2920.

4. Li Y, Welm B, Podsypanina K, Huang S, Chamorro M, Zhang X, Rowlands T, Egeblad M, Cowin P, Werb Z, Tan LK, Rosen JM, Varmus HE: Evidence that transgenes encoding components of the Wnt signaling pathway preferentially induce mammary cancers from progenitor cells. Proc Natl Acad SciU SA 2003, 100:15853-15858.

5. Liu BY, McDermott SP, Khwaja SS, Alexander CM: The transforming activity of Wnt effectors correlates with their ability to induce the accumulation of mammary progenitor cells. Proc Natl Acad Sci U S A 2004, 101:4158-4163.

6. Shackleton M, Vaillant F, Simpson KJ, Stingl J, Smyth GK, Asselin-Labat ML, Wu L, Lindeman GJ, Visvader JE: Generation of a functional mammary gland from a single stem cell. Nature 2006, 439:84-88.

7. Cho RW, Wang X, Diehn M, Shedden K, Chen GY, Sherlock G, Gurney A, Lewicki J, Clarke MF: Isolation and molecular characterization of cancer stem cells in MMTV-Wnt-1 murine breast tumors. Stem Cells 2008, 26:364-371. 
8. Klaus A, Birchmeier W: Wnt signalling and its impact on development and cancer. Nat Rev Cancer 2008, 8:387-398.

9. Matushansky I, Maki RG, Cordon-Cardo C: A context dependent role for Wnt signaling in tumorigenesis and stem cells. Cell Cycle 2008, 7:720-724.

10. Zeng YA, Nusse R: Wnt proteins are self-renewal factors for mammary stem cells and promote their long-term expansion in culture. Cell Stem Cell 2010, 6:568-577.

11. Visvader JE: Keeping abreast of the mammary epithelial hierarchy and breast tumorigenesis. Genes Dev 2009, 23:2563-2577.

12. Lim E, Wu D, Pal B, Bouras T, Asselin-Labat ML, Vaillant F, Yagita H, Lindeman GJ, Smyth GK, Visvader JE: Transcriptome analyses of mouse and human mammary cell subpopulations reveal multiple conserved genes and pathways. Breast Cancer Res 2010, 12:R21.

13. Rieger ME, Sims AH, Coats ER, Clarke RB, Briegel KJ: The embryonic transcription cofactor LBH is a direct target of the Wnt signaling pathway in epithelial development and in aggressive basal subtype breast cancers. Mol Cell Biol 2010, 30:4267-4279.

14. Briegel KJ, Joyner AL: Identification and characterization of Lbh, a novel conserved nuclear protein expressed during early limb and heart development. Dev Biol 2001, 233:291-304.

15. Howe LR, Watanabe O, Leonard J, Brown AMC: Twist is up-regulated in response to Wnt1 and inhibits mouse mammary cell differentiation. Cancer Res 2003, 63:1906-1913.

doi:10.1186/bcr2631

Cite this article as: Many AM, Brown AMC: Mammary stem cells and cancer: roles of Wnt signaling in plain view. Breast Cancer Research 2010, 12:313. 